\title{
Monsoon cycle influences on catch and size of blue swimming crabs (Portunus pelagicus) from crab gillnets in Phetchaburi Province
}

\author{
Supatcha Lurkpranee $^{\mathrm{a}}$, Krerkkrai Songin ${ }^{\mathrm{a}}$, Sansanee Wangvoralak ${ }^{\mathrm{a}}$, Urairathr Nedtharnn ${ }^{\mathrm{a}}$, \\ Monissa Srisomwong ${ }^{\mathrm{a}}$, Jirarpast Adjimangkunl ${ }^{\mathrm{a}}$, Shettapong Meksumpun ${ }^{\mathrm{b}}$, Charumas Meksumpun ${ }^{\mathrm{c}}$ \\ a Department of Fishery Management, Faculty of Fisheries, Kasetsart University, Bangkok 10900 Thailand \\ b Department of Marine Science, Faculty of Fisheries, Kasetsart University, Bangkok 10900 Thailand \\ c Department of Fishery Biology, Faculty of Fisheries, Kasetsart University, Bangkok 10900 Thailand
}

*Corresponding author, e-mail: krerkkrai_so@outlook.com

Received 11 Jul 2020

Accepted 6 May 2021

\begin{abstract}
Portunus pelagicus is a crucial resource of Thailand and a large portion of the catch comes from artisanal fisheries. The aims of this study were to elucidate fishing practices and identify the effects of driving factors on catch in terms of quantity and quality of $P$. pelagicus caught by crab gillnets in Phetchaburi Province. Samples were collected from January 2018 to February 2019. In both upper and lower areas of Phetchaburi Province, the lowest catch per unit effort (CPUE) was found in the northeast monsoon season, while the highest was found in the pre-monsoon. The results indicated an interaction between areas, seasons, and mesh sizes on log CPUE, and the log CPUE was generally lower in the northeast monsoon season in both areas and groups of mesh sizes. The size of P. pelagicus by carapace width ranged from 5.5 to $17.0 \mathrm{~cm}$ with the median \pm interquartile of $11.0 \pm 1.0 \mathrm{~cm}$. The crab size in the upper area was smaller than in the lower area in all seasons and the crab size in the southwest monsoon season was larger than in the other seasons for both areas. The median sizes were larger than the first maturity size of $9.5 \mathrm{~cm}$ in almost all the months, except October, in the upper area (median carapace width \pm interquartile $=9.0 \pm 0.8 \mathrm{~cm}$ ).
\end{abstract}

KEYWORDS: blue swimming crab, catch per unit effort, crab gillnet, Gulf of Thailand

\section{INTRODUCTION}

Many species of marine resources are highly or overly exploited and impacted by various environmental threats world wild [1]. Throughout history, marine resources were exploited by fisheries which can cause devastating effects on their population, some of which has become threaten, endangered or extinct [2]. The declining of marine catch from unsustainable fisheries not only reflects concerning situation of abundance of species, it also affects economy and food security [3]. In order to cope with the issue of overfishing, understanding local fisheries and their exploited populations are crucial for effective conservation and fisheries management [4].

Crabs are important resources globally, but many populations have been suffered from overfishing and illegal, unreported, and unregulated (IUU) fishing [5]. One of the widely distributed species, Portunus pelagicus found in the Indo-Pacific Region, is an important source of food and income in many developing countries [6]. In Thailand, $P$ pelagic has been the highest wild caught species of crustacean for more than a decade; and the most production (76.5\% in 2017) are from the Gulf of Thailand [7]. They have contributed for $90.5 \%$ of total crab production by artisanal fisheries and $86.8 \%$ of all crab caught by commercial scaled fisheries in the Gulf of Thailand in 2018 [8,9].

Seasonal variation can have an impact on benthic community abundance and their fisheries [10]. $P$. pelagicus distribution in various regions has been found to be seasonally dynamic. Their migration is driven by food availability and reproduction, which relate to seasonal dynamics of temperature and salinity, and can affect fisheries on their quantity and quality of catch [11]. Weather conditions can also directly affect fisheries, as strong current and wind in monsoon seasons posing a threat to fisher safety, especially smaller vessels and, therefore, affecting catch in the seasons [12].

Demography of the same marine species can be diverse among locations due to the variation of 
habitat conditions [13]. The difference life stages of P. pelagicus have variated habitat preferences due to their changes in diet as they become mature and, as a result, they move further offshore [14]. Areas with different depth and habitat substrates, which variate crab population, could provide catch differently for fisheries [15].

Artisanal or small-scale fisheries are important as a livelihood which provide food and income for coastal communities and the majority of fishermen in Thailand [16]. More than half of the total $P$. pelagicus catch are from this artisanal fisheries, estimated to be $50.4 \%$, and the majority of the production $(75.9 \%$ in 2018) are from the Gulf of Thailand caught by crab gillnets $[8,9]$. Phetchaburi Province has been recorded to have the second highest number of crab gillnet fishing boats registered in the Inner Gulf of Thailand [17]. Despite their large number and contribution in production and potential impacts on $P$. pelagicus population, artisanal fisheries in Thailand have not been studied comprehensively. The investigation of catch variation by fishermen among areas and periods of time could be beneficial for implementing appropriate fisheries management.

Given the above data, the aims of this study were to elucidate fishing practices and identify key driving factors affecting catch of $P$. pelagicus in terms of quantity and quality. This would be useful for constructing an effective management for sustainability in production of crab gillnet fishery.

\section{MATERIALS AND METHODS}

\section{Study areas}

The study areas were classified as upper and lower areas of Phetchaburi Province (Fig. S1). The classification was based on rapid rural appraisal (RRA) on local fishing communities. From the RRA, the differences can be demonstrated as follows. Crab gillnets with larger mesh size $(10-11 \mathrm{~cm})$ were more commonly used in the lower area, while smaller mesh sizes $(8-9 \mathrm{~cm})$ were more preferred in the upper area. Fishermen in the lower area usually did not operate in the northeast monsoon season, unlike the upper area. Fishermen operated within their respective area and did not cross the area boundary. Samples were collected from 7 sampling sites at fishing ports. The upper area consisted of 3 sampling sites, one in each Sub-districts of Bang Kaeo, Laem Phak Bia, and Hat Chao Samran. The lower area consisted of 4 sampling sites, one each from Nong Khanan, Puek Tian, Bang Kao, and Cha- am Sub-districts.

\section{Sample collection}

Samples were collected monthly from January 2018 to February 2019 covering three seasons. According to the Thai Meteorological Department and the information collected from RRA, two monsoon seasons can be identified, with a gap or pre-monsoon season in-between, in the local scale of Phetchaburi Province. The pre-monsoon season ranged from February to May when the weather was considered the mildest and allowed fishermen to operate most days of the months. The southwest monsoon season was from June to September, while the northeast monsoon season ranged from October to January, when the weather was the most volatile and prevented local fishermen, especially in the lower area, from operating in most days. Quantity of total catch from each sampled fisherman was documented when landed at fishing ports. In cases where fishermen did not classify and separate $P$. pelagicus from other catches, a quarter of total catch would be sampled by cluster sampling. Catch samples were identified by their species, and their size and weight were measured. Stratified random sampling was used in cases where P. pelagicus was separated from other catches and, then, sorted by size.

Biological characteristics of $P$. pelagicus samples were collected for size, weight, sex, and stage of external eggs. Size measurement was done using carapace width to the finest scale of $0.5 \mathrm{~cm}$. Weight measurement was done in the scale of gram. Stages of external egg, if existed, were classified by colours, i.e. yellow, orange, brown, and black, in order of maturity.

The details of fishing gears and fishing practices of individual fishermen were collected by interviewing. These included type of fishing gears, number of gears used, size of gears, mesh size, vessel size and engine, distance of fishing areas from shore, operating depth, and time of operation. Crab gillnet mesh sizes were classified into two groups, $8-9 \mathrm{~cm}$ and $10-11 \mathrm{~cm}$, which were found to be used by fishermen in the area.

\section{Data analyses}

Catch per unit effort (CPUE) was estimated from total weight of $P$. pelagicus divided by fishing effort, which was calculated by standard total crab gillnet length and number of operational days in the areas of study. The total crab gillnet length of each fisher was calculated by multiplying the length of their 
gillnet with number of gillnets per pack and number of packs. The number of operational days was the period when crab gillnets were left to catch crabs and recovered. When the distribution of total crab gillnet length and the number of operational days were not normal, the use of median for the estimation of standard total crab gillnet length and standard number of operational days of all fishermen was applied. The medians of number of operational days were the same, at 2 days, across all areas and seasons. Therefore, the same standard number of operational days was used to calculated CPUE for all samples.

The total crab gillnet length was tested through non-parametric analyses to identify if there was a significant different among areas or seasons, and to clarify if there was a need for utilizing different standard total crab gillnet length and number of operational days to derive CPUE. Mann-Whitney test was used to investigate the differences among upper and lower areas, while Kruskal-Wallis test was used for analysing the variation among seasons.

For the test of the effect of areas, seasons, and mesh sizes on CPUE, the estimated CPUE was transformed through logarithm to satisfy the assumption of homogeneity of variance. Five highest and five lowest values were excluded from the analysis to eliminate an outliner effect. Then ANAOVA was used to test the interaction and main effects of areas, seasons, and mesh sizes on log CPUE at the significant level of 0.05. In the lower area, northeast monsoon season only included samples in December and January for the analysis because there was no crab-gillnet fishermen operating in October and November when the sampling was conducted.

For the study of the effects, of areas, seasons and mesh sizes on $P$. pelagicus size, non-parametric tests were required for statistical analyses due to the size was unable to be transformed to meet assumptions of normality or homogeneity of variance. Wilcoxon signed-rank test was used to compare crab sizes in each month to first maturity size of $9.5 \mathrm{~cm}$ [18]. The difference of size among areas and mesh sizes was tested using Mann-Whitney test. The difference of size among seasons was tested by Kruskal-Wallis test with post hoc test of Dunn-Bonferroni's test. The significant level of all tests was 0.05. Samples from the lower area in northeast monsoon season only were those in December and January due to the lack of catch in October and November.
Table 1 Results of NOVA testing effects of areas, mesh sizes, and seasons on log CPUE of $P$. pelagicus caught by crab gillnet in Phetchaburi Province.

\begin{tabular}{lcccr}
\hline Source & SS & d.f. & $F$ & $p$-value \\
\hline Area & 0.023 & 1 & 0.264 & 0.607 \\
Mesh size & 0.380 & 1 & $4.296^{*}$ & 0.039 \\
Season & 4.990 & 2 & $28.186^{*}$ & $<0.001$ \\
Area*Mesh size & 0.371 & 1 & $4.193^{*}$ & 0.041 \\
Area*Season & 0.392 & 2 & 2.216 & 0.111 \\
Mesh size*Season & 0.664 & 2 & $3.751^{*}$ & 0.025 \\
Area*Mesh size*Season & 1.793 & 2 & $10.129^{*}$ & $<0.001$ \\
Residual & 27.973 & 316 & & \\
\hline
\end{tabular}

" on $F$-value indicates a statistical significance at the significant level of 0.05 .

\section{RESULTS}

From the survey along the coast of Phetchaburi Province, 374 catch samples from artisanal crab gillnets were found. Among them, 337 samples were for $P$. pelagicus. The number of fishermen who landed with $P$. pelagicus catch was varied among areas and times. The total number of catch samples in the upper area $(n=209)$ was higher than those in the lower area $(n=128)$. Consistent with the RRA, crab gillnets with 8-9 $\mathrm{cm}$ mesh size were more common in the upper area than in the lower area with the percentage of total samples of $68.5 \%$ and $55.2 \%$, respectively. The median of depth where crab gillnets were placed was $6 \mathrm{~m}$ in both areas.

The landed catch components consisted mainly of $P$. pelagicus with the mean of $90.9 \%$ of total catch. The most common landed bycatch was benthic fish with the mean of $6.7 \%$ of total catch, followed by other crabs $(0.7 \%)$, shrimps $(0.6 \%)$, and pelagic fish $(0.5 \%)$. All the other bycatches, including bivalves, gastropods, and cephalopods, were about $0.6 \%$.

\section{Catch per unit effort}

There was no significant difference of total crab gillnet length among areas $(\mathrm{Z}=-1.720, p$-value $=$ $0.086)$, nor among seasons $\left(\chi^{2}=0.078, p\right.$-value $=$ $0.962)$. Therefore, the standard total crab gillnet length of $2880 \mathrm{~m}$ was used to calculate CPUE across all areas and seasons. For $P$. pelagicus, the CPUE varied from 0.004 to $0.43 \mathrm{~kg} / \mathrm{day} / 100 \mathrm{~m}$. The overall mean of CPUE was $0.10 \mathrm{~kg} /$ day $/ 100 \mathrm{~m}$ (Fig. 1). The highest mean CPUE in the upper area was found in April 2018, and the lowest was in December 2018. In the lower area, the highest mean CPUE was in March 2018, and the lowest was in December 2018. There was no catch in October and 

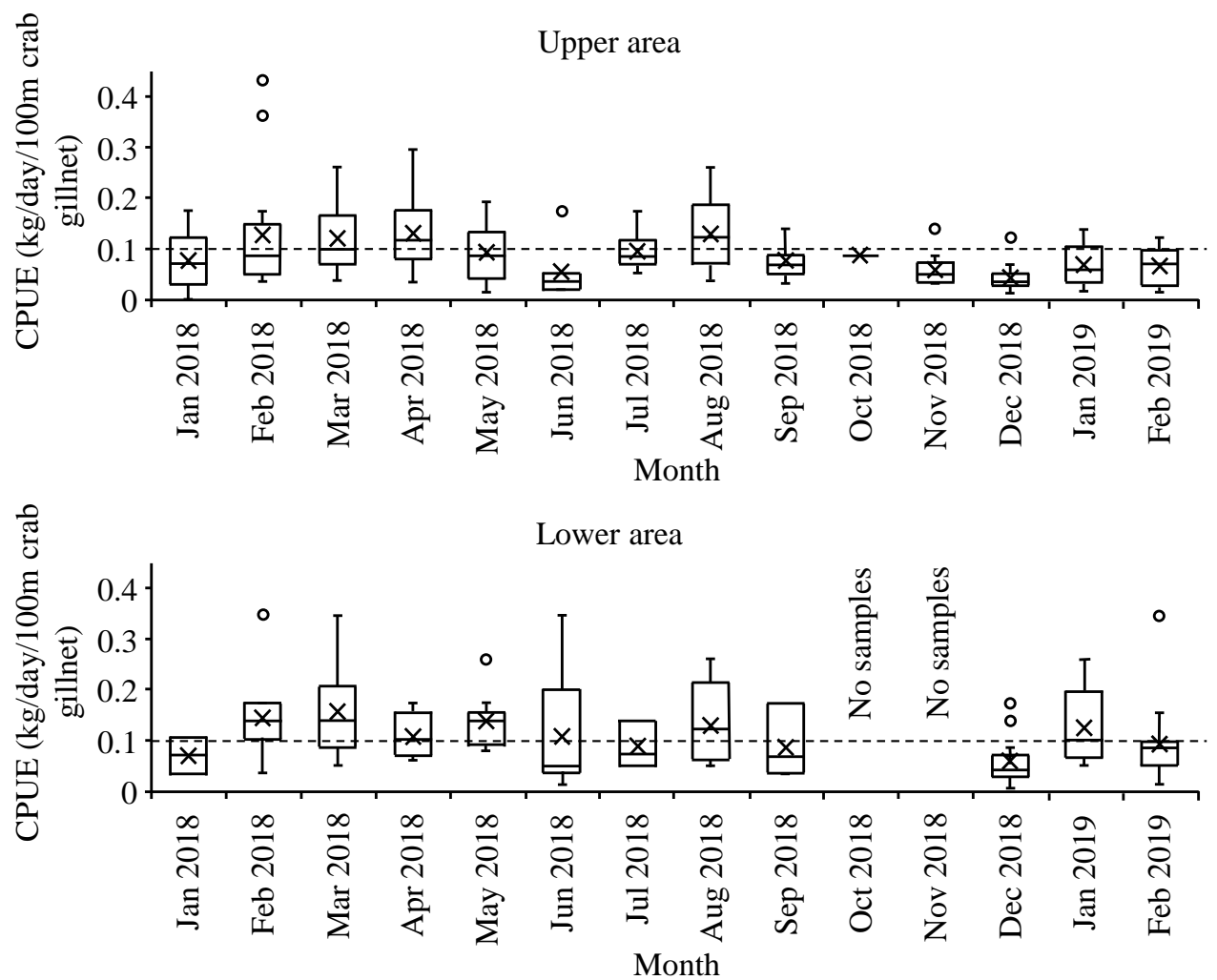

Fig. 1 Monthly catch per unit effort (CPUE) of P. pelagicus by crab gillnets in the upper and the lower areas of Phetchaburi Province from January 2018 to February 2019. Box plots represent the median ( - ) falling between upper and lower quartile (box limits); vertical lines represent extent of the data; circles (o) represent individual outliers; and crosses $(\times)$ represent means; dash lines represent overall mean at $0.1 \mathrm{~kg} /$ day $/ 100 \mathrm{~m}$. No samples were collected in the lower area in October and November 2018 due to no fishing operated.

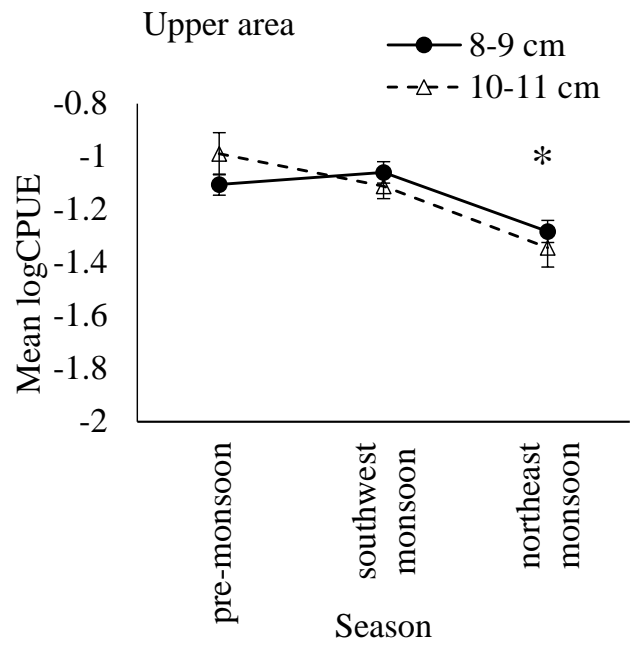

Lower area

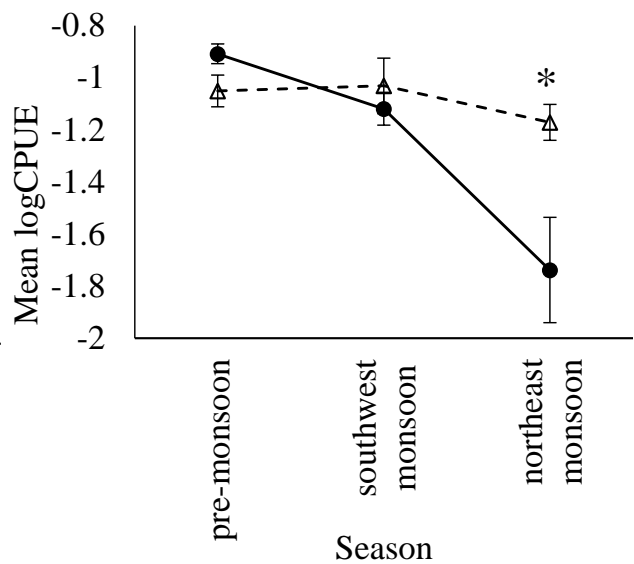

Fig. 2 Log CPUE of $P$ pelagicus caught by crab gillnets with the mesh size of $8-9 \mathrm{~cm}$ and $10-11 \mathrm{~cm}$ in the upper and lower areas of Phetchaburi Province in three seasons. The CPUE unit is kg/day/100 m. Stars (*) represent statistically significant interactions at the significant level of 0.05 . 
Table 2 Results of Wilcoxon sign-rank test of $P$. pelagicus carapace width comparing with first maturation size of $9.5 \mathrm{~cm}$.

\begin{tabular}{lrrrr}
\hline Month & $n$ & Median $(\mathrm{cm})$ & \multicolumn{1}{c}{ Z } & $p$-value \\
\hline January 2018 & 388 & $11.5 \pm 0.75$ & $15.791^{*}$ & $<0.001$ \\
February 2018 & 655 & $11 \pm 0.75$ & $18.241^{*}<0.001$ \\
March 2018 & 1256 & $10.5 \pm 1.00$ & $22.259^{*}$ & $<0.001$ \\
April 2018 & 502 & $10.5 \pm 0.75$ & $16.257^{*}$ & $<0.001$ \\
May 2018 & 683 & $11 \pm 1.00$ & $20.539^{*}$ & $<0.001$ \\
June 2018 & 350 & $12 \pm 1.75$ & $14.050^{*}$ & $<0.001$ \\
July 2018 & 358 & $12 \pm 1.25$ & $15.981^{*}<0.001$ \\
August 2018 & 790 & $11 \pm 1.25$ & $19.925^{*}<0.001$ \\
September 2018 & 700 & $12 \pm 1.25$ & $20.473^{*}<0.001$ \\
October 2018 & 142 & $9 \pm 0.75$ & $-2.020^{*}$ & 0.043 \\
November 2018 & 415 & $10 \pm 0.75$ & $7.866^{*}<0.001$ \\
December 2018 & 672 & $11.5 \pm 1.00$ & $21.589^{*}<0.001$ \\
January 2019 & 411 & $11 \pm 1.00$ & $14.865^{*}<0.001$ \\
February 2019 & 770 & $11 \pm 1.00$ & $20.294^{*}<0.001$
\end{tabular}

" on $Z$-value indicates a statistical significance at the significant level of 0.05 .

November 2018 in the lower area as fishermen were unable to operate under severe weather of northeast monsoon in less sheltered area.

The ANOVA showed a significant interaction between areas, mesh sizes, and seasons (Table 1). The most noticeable result was that log CPUE from catch in the northeast monsoon season from both areas and groups of mesh sizes was lower than in the other seasons with the one from the lower area by 8-9 $\mathrm{cm}$ mesh size being the lowest (Fig. 2). The result from post hoc test confirmed that log CPUE in the northeast monsoon season was significantly lower than the other seasons, apart from the one from the lower area by mesh size of $10-11 \mathrm{~cm}$. The $\log$ CPUE from the lower area by $8-9 \mathrm{~cm}$ mesh size in pre-monsoon season was significantly higher than all the others. The differentiation of log CPUE from other combinations of area, mesh size and season was not obvious.

\section{Size}

A total of 8092 P. pelagicus individuals were sampled with $58.34 \%$ male, $40.84 \%$ female, and $0.82 \%$ unidentified sex. Crab size was commonly larger than $9.5 \mathrm{~cm}$ from monthly survey except in October 2018 where it was significantly smaller (Table 2). Larger crabs were generally found in the southwest monsoon season. The proportion of crabs over $9 \mathrm{~cm}$ size class was higher in the lower area in every month excepts in October and November when there was no sample in the lower area for

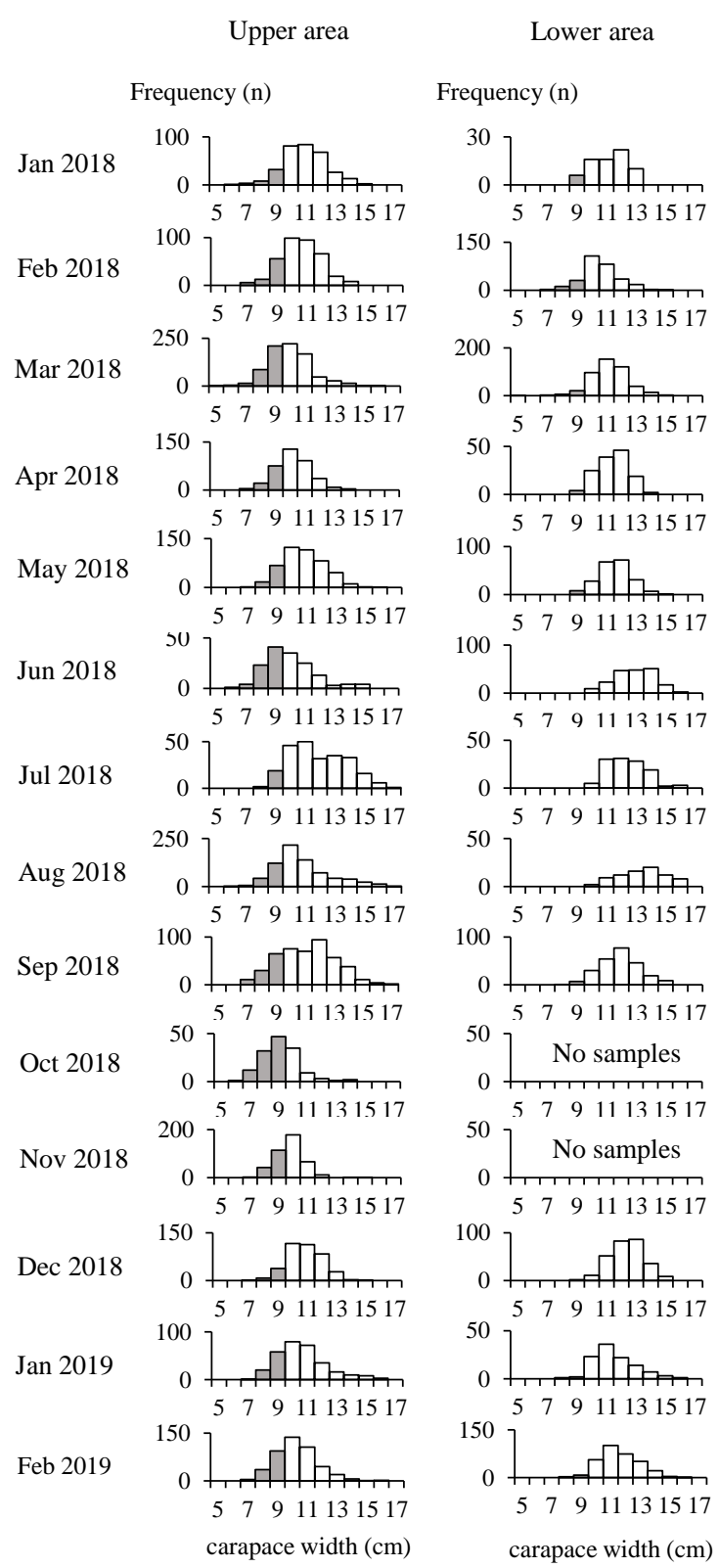

Fig. 3 Histogram plots of P. pelagicus sizes from the upper and lower areas of Phetchaburi Province from January 2018 to February 2019. Grey bars indicate the carapace width within the size class of $9 \mathrm{~cm}$ and smaller. White bars indicate size classes larger than $9 \mathrm{~cm}$. No samples were collected in the lower area in October and November 2018 due to no fishing operated. Frequency scales are varied by months.

the comparison (Fig. 3). More than half of the upper area crabs in October were within $9 \mathrm{~cm}$ size class and under. Females with external eggs were 
Upper area

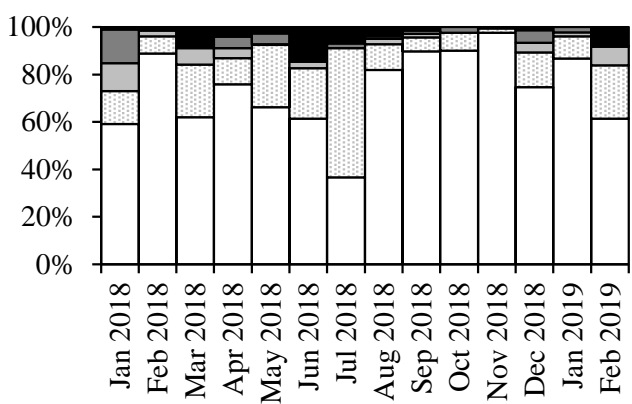

Lower area

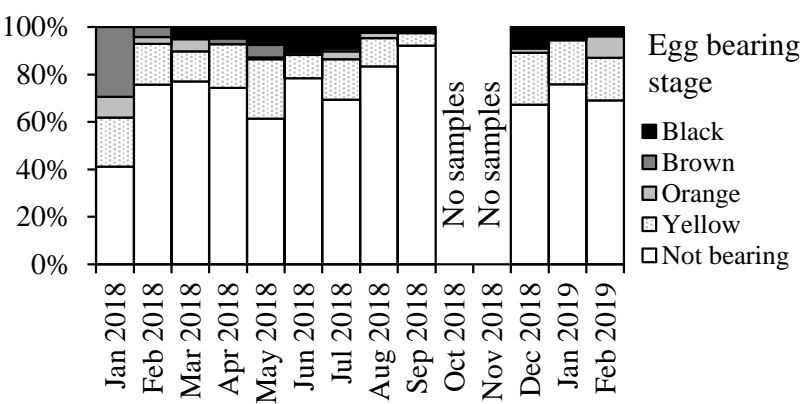

Fig. 4 Proportion of egg baring crabs of female P. pelagicus from the upper and the lower areas of Phetchaburi Province sampled from January 2018 to February 2019. The maturity of external eggs was classified by egg colours into four stages.

a)

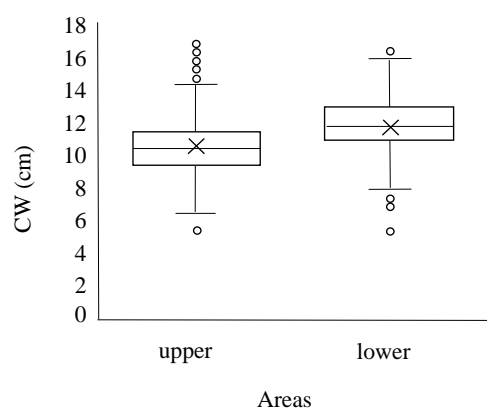

b)

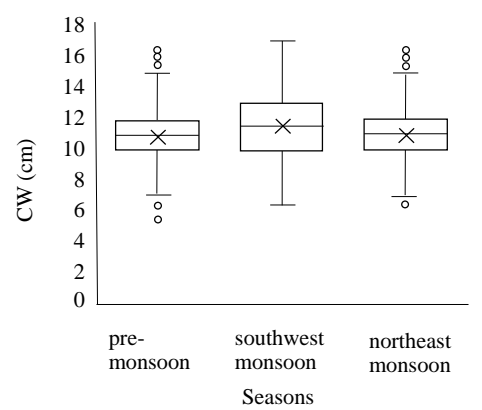

c)

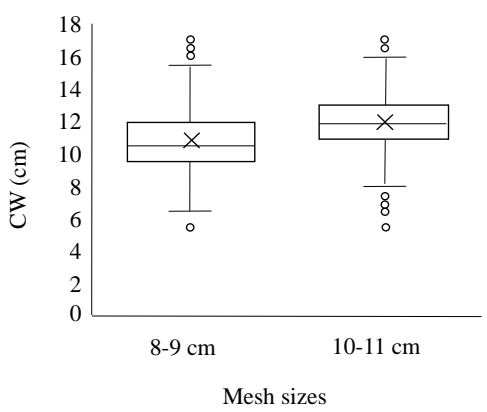

Fig. 5 Sizes of $P$. pelagicus caught by areas (a), seasons (b), and mesh sizes (c). Box plots represent the median (-) falling between upper and lower quartile (box limits); vertical lines represent extent of the data; circles (o) represent individual outliers; and crosses $(x)$ represent means.

found in every month, but did not exceed 50\% of all females except in July 2018 in the upper area and in January 2018 in the lower area (Fig. 4). This result indicated possible multiple reproductive peaks in the southwest and northeast monsoon seasons.

The size of crabs was significantly different among areas $(\mathrm{Z}=-32.211, p$-value $<0.001)$, seasons $\left(\chi^{2}=221.584, p\right.$-value $\left.<0.001\right)$, and mesh sizes $(Z=-28.378, p$-value $<0.001)$. The crabs in the lower area, with the median of $12.0 \pm 1.0 \mathrm{~cm}$, were larger than those in the upper area $(10.5 \pm 1.0 \mathrm{~cm})$ (Fig. 5). For the differences among seasons, the post hoc test showed that the size of crabs in the southwest monsoon season $(11.5 \pm 1.5 \mathrm{~cm})$ was significantly larger than in the pre-monsoon season $(11.00 \pm 1.00 \mathrm{~cm})(\mathrm{Z}$ $=-14.485, p$-value $<0.001)$ and in the northeast monsoon season $(11.00 \pm 1.00 \mathrm{~cm})(\mathrm{Z}=10.871, p$ value $<0.001)$. The sizes of catch in the premonsoon and the northeast monsoon seasons were not significantly different $(Z=-1.905, p$-value $=$ 0.057). The size of crabs caught by crab gillnet with the mesh size of $10-11 \mathrm{~cm}(11.8 \pm 1.0 \mathrm{~cm})$ was larger than those from the $8-9 \mathrm{~cm}$ mesh size $(10.5 \pm 1.3 \mathrm{~cm})$.

\section{DISCUSSION}

The overall size of $P$. pelagicus was larger than the first maturity size of $9.5 \mathrm{~cm}$ from a study in the Upper Gulf of Thailand [18]. When compared the size of $P$. pelagicus and the average CPUE in this study with the results in another study on crab gillnets in Petchaburi Province in 2005, the size in this study was close to the 2005 result, which was $10.93 \mathrm{~cm}$ on average, and the average CPUE in this study was lower than half of the 2005, which was $0.21 \mathrm{~kg} /$ day $/ 100 \mathrm{~m}$ crab gillnet [19]. This could be a sign of a decline in abundance of population, which is consistent with the drastically decline on the annual total catch of $P$. pelagicus in the Gulf 
of Thailand during the past two decades [7]. The number of crab gillnet vessels in the area has also increased from 1281 in 2007 to 4792 in 2015 [17]. The increase in number of fishing vessels could introduce higher fishing effort, resulting in lower CPUE.

The size and catch variation between the upper and the lower areas could occur due to differences in local physical habitat conditions and nutrients. The upper area is located near the mouth of Mae Klong River, Bang-tabun River, and Phetchaburi River which discharge sediment to the coast and create a shallower seabed with higher composition of silt compared with the lower area [20]. Moreover, topography of the area shows a greater depth in the lower area than the upper area [21]. The depth and substrates could affect the abundance and the size of invertebrates in benthic community, including crabs and their sources of diet such as polychaetes residing in the area [22]. The higher concentration of nutrients from runoff discharge in the upper area could generate higher productivity and food abundance, which could be a suitable nursery ground for juvenile crabs [23]. P. pelagicus commonly move into deeper sea as they age [24]. In other parts of Thailand, they have been found to be larger in deeper areas of the sea due to their differences of feeding ecology in life stages, which makes larger crabs move to the deeper areas for their suitable diet [25].

Environmental conditions, such as nutrient concentration and changes from seasonal variation, were known to affect population of marine species including invertebrate via food availability [26]. In other areas within the Gulf of Thailand, the diet composition of $P$. pelagicus was different between seasons and consisted with teleost fish and crustaceans from the middle of pre-monsoon to the beginning of northeast monsoon seasons due to the higher abundance of preys [27]. The concentration of nitrogen and phosphorus in the area during the southwest monsoon season was observed to be higher than in other seasons, which could result in higher productivity and food availability for crab growth. Larger P. pelagicus in Phetchaburi Province could be foraging in the greater depth for their preferable diet in the seasons when the abundance of food in the shallow area was scarce and moved closer to the coast in the late pre-monsoon season where nutrient and productivity started to increase [28].

Portunus spp. commonly breed all year round in tropical environment with seasonal peaks [29]. This is consistent with the finding in this study where females baring external eggs were found all year with higher numbers in some months. P. pelagicus was found to move offshore to their spawning grounds in many areas including other parts of the Gulf of Thailand [30]. The salinity in the area of Phetchaburi Province, especially in the upper area located closer to Phetchaburi, Bang-tabun, and Mae Klong Rivers, was found to decrease by the effect of runoff in the late southwest monsoon season [31]. This could cause adult $P$. pelagicus to migrate offshore to their spawning ground until they relocated back closer to the coast in the pre-monsoon season where salinity and temperature increased to a preferable condition [28]. The movement into the deeper area, further from the coast, could raise difficulty for harvesting especially for artisanal fisheries with their limitation to pursue the crabs [32]. This could explain the lower CPUE in the late southwest and the northeast monsoon seasons. However, P. pelagicus spawning movements cannot be concluded by this study as samples were obtained from artisanal fishing with limitation in accessibility to deeper part of the sea.

Other than the obstacle of going further to catch crabs in their spawning area in the spawning season, the northeast monsoon season could also pose a threat to safety of fishermen and their fishing gears [33]. Harsh weather condition and entanglement with other fishing gears in the area could result in damages or losses of gillnets [34]. However, the effect of seasonal changes varied among places [35]. In this case, fishermen in the upper area did not need to apply as much caution with the weather compared with the lower area due to the less severe effects of the monsoon in their natural bay structure. This clearly reflected in the number of fishermen found operating in October and November in the upper area, while there was none encountered in the lower area [36]. The CPUE in this period of the year was lower than the overall average value, which could be due to the absence of larger crabs in the accessible fishing grounds. The movement of spawning crabs could also be responsible for the smaller size of catch in the northeast monsoon season where it was still viable, resulting in more than half of crabs caught in the upper area in October being smaller than the first maturity size of $9.5 \mathrm{~cm}$ from a study in the nearby area [18].

Smaller mesh sizes generally have higher selectivity for smaller individuals [37]. In this study, the smaller mesh sizes were more dominant in the upper area, because they allowed fishermen to catch 
smaller crabs and gain similar CPUE to the lower area. The size selectivity of fishing gears should be considered for the benefit in both biological and socioeconomic aspects [38]. The appropriate size of catch should be considered along with the first maturity size of $P$. pelagicus, which could be varied among locations [39]. In the nearby area of the Upper Gulf of Thailand, maturity size was estimated at $9.5 \mathrm{~cm}$ [18], while it was $7.5 \mathrm{~cm}$ in the Eastern Gulf of Thailand in Chanthaburi Province [40]. In this study, the majority of crabs caught by both groups of mesh size were larger than the aforementioned first maturity sizes. On economic aspect, the larger mesh size provides larger crabs, which are more valuable and could potentially provide fishermen with more income while having no drastic decline in total CPUE [41].

\section{CONCLUSION}

In conclusion, quantity of catch and crab size can be varied by habitat conditions, seasons, and mesh sizes. The main driving factor effecting CPUE and size of $P$. pelagicus was seasonality because it could majorly affect the ecosystem surrounding crabs and their behaviours. As there is no robust information of population dynamics and fishing impacts in the area, fishery management should be proceeded cautiously. The maturity size of $P$. pelagicus in the area of Phetchaburi Province should be investigated to verify if the common size of crabs caught using crab gillnets is sustainable. Then, minimum crab size should be established in the regulation accordingly to ensure a reproduction opportunity before being caught. This measure could particularly work well with this type of fishing as crabs would normally be alive after taking out from the gillnet, making it possible to release the undersized individuals back to the water and discard issues is also mitigated. Moreover, a possibility of setting up a nursery ground in the upper area of Phetchaburi Province where smaller crabs were more common should be investigated. During the northeast monsoon season, especially in October, a seasonal closure in the upper area should be considered with the reason that the majority of crabs caught in this period were smaller than $9.5 \mathrm{~cm}$ with low CPUE. Moreover, the spawning season along with the spawning grounds should be validated for a precise implementation of seasonal and area closures. This will minimize the impact of regulation on fishermen while still allow crabs to reproduce without disturbances and provide higher recruitment to ensure a sustainable production.

\section{Appendix A. Supplementary data}

Supplementary data associated with this article can be found at http://dx.doi.org/10.2306/ scienceasia1513-1874.2021.060.

Acknowledgements: We highly appreciate the cooperation on data collection from all fishermen and ports in Phetchaburi Province. We are grateful for the funding support from the Thailand Research Fund. We also wish to thank all members of the Faculty of Fisheries, Kasetsart University who assisted us during the fieldwork.

\section{REFERENCES}

1. Hilborn R, Fulton EA, Green BS, Hartmann K, Tracey SR, Watson RA (2015) When is a fishery sustainable? Can J Fish Aquat Sci 72, 1433-1441.

2. Roberts C (2010) The Unnatural History of the Sea, Island Press, Washington DC, USA.

3. Pauly D, Zeller D (2016) Catch reconstructions reveal that global marine fisheries catches are higher than reported and declining. Nat Commun 7, ID 10244.

4. Beverton RJ, Holt SJ (2012) On the Dynamics of Exploited Fish Populations, Vol 11, Springer Science \& Business Media, Lowestoft, UK.

5. Petrossian G, Weis JS, Pires SF (2015) Factors affecting crab and lobster species subject to IUU fishing. Ocean Coast Manag 106, 29-34.

6. FAO (2019) Fishery and Aquaculture Statistics 2017, FAO, the United Nations, Rome.

7. Department of Fisheries (2019) Fisheries Statistic of Thailand 2017, 9th edn, Department of Fisheries, Ministry of Agriculture and Cooperatives, Bangkok, Thailand. [in Thai]

8. Department of Fisheries (2019) Marine Capture Production of Commercial Fishery 2018, Vol 5, Department of Fisheries, Ministry of Agriculture and Cooperative, Bangkok, Thailand. [in Thai]

9. Department of Fisheries (2019) Statistics of Aquatic Animals Catch from Artisanal Fishing 2018, Vol 6, Department of Fisheries, Ministry of Agriculture and Cooperatives, Bangkok, Thailand. [in Thai]

10. Varadharajan D, Soundarapandian P, Gunalan B, Babu R (2010) Seasonal abundance of macro benthic composition and diversity along the south east coast of India. Eur J Appl Sci 2, 1-5.

11. Ikhwanuddin M, Azra MN, Talpur MA, Abol-Munafi $A B$, Shabdin ML (2012) Optimal water temperature and salinity for production of blue swimming crab, Portunus pelagicus 1st day juvenile crab. Aquacult Aquarium Conserv Legis 5, 4-8.

12. Hussain MR, Rahman AA, Yusuff RM, Latif N, Rashid S, Abdullah H (2014) Issues on occupational safety and health at workplace among older fishermen in malaysia. J Occup Saf Health 11, 57-62.

13. Cappo M, Marriott RJ, Newman SJ (2013) James's rule and causes and consequences of a latitudinal 
cline in the demography of John's Snapper (Lutjanus johnii) in coastal waters of Australia. Fish Bull 111, 309-324.

14. Zainal KA (2013) Natural food and feeding of the commercial blue swimmer crab, Portunus pelagicus (Linnaeus, 1758) along the coastal waters of the Kingdom of Bahrain. J Assoc Arab Univ Basic Appl Sci $13,1-7$.

15. Asphama AI, Amir F, Malina AC, Fujaya Y (2015) Habitat preferences of blue swimming crab (Portunus pelagicus) species complex. Aquac Indones 16, 10-15.

16. Chuenpagdee R, Juntarashote K (2011) Learning from the experts: Attaining sufficiency in small-scale fishing communities in Thailand. In: Jentoft S, Edie A (eds) Poverty Mosaics: Realities and Prospects in Small-Scale Fisheries, Springer, Dorrecht, The Natherland, pp 309-331.

17. Department of Fisheries (2016) Thai Fishing Vessels Statistics 2015, Vol 2, Department of Fisheries, Ministry of Agriculture and Cooperative, Bangkok, Thailand. [in Thai]

18. Jindalikit J (2008) Biology and Stock Assessment of Blue Swimming Crab Portunus pelagicus (Linnaeus, 1758) in the Upper of Thailand, Technical Paper No. 3, Department of Fisheries, Ministry of Agriculture and Cooperative, Bangkok, Thailand. [in Thai]

19. Wungkhahart W, Srikum T, Awaiwanont K, Srichanngam S, Siripech A, Arleuroadprapai C, Loychuen K (2007) Crab Gill Net Fishery, Technical Paper No. 13, Department of Fisheries, Ministry of Agriculture and Cooperative, Bangkok, Thailand. [in Thai]

20. Negri MP, Sanfilippo R, Basso D, Rosso A (2015) Comparison of live and dead molluscan assemblages suggests recent human-driven decline in benthic diversity in Phetchaburi (NW Gulf of Thailand). Cont Shelf Res 111, 9-30.

21. Hydrographic Department Royal Thai Navy (2014) Nautical Map Number 001 Prachuap Khiri Khan to Ko Chuang, Hydrographic Department, Royal Thai Navy, Bangkok, Thailand. [in Thai]

22. Ponti M, Casselli C, Abbiati M (2011) Anthropogenic disturbance and spatial heterogeneity of macrobenthic invertebrate assemblages in coastal lagoons: The study case of Pialassa Baiona (northern Adriatic Sea). Helgol Mar Res 65, 25-42.

23. Tantichaiwanit W, Gajaseni N, Piumsomboom A, Kunsook C (2010) Zooplankton dynamics and appropriate management approach for blue swimming crab in Kung Krabaen Bay, Thailand. In: Hoanh CT, Szuster BW, Suan-Pheng K, Ismail AM, Noble AD (eds) Tropical Deltas and Coastal Zones, CPI Antony Rowe Ltd., Chippenham, UK, pp 106-116.

24. Lai JC, Ng PK, Davie PJ (2010) A revision of the Portunus pelagicus (Linnaeus, 1758) species complex (Crustacea: Brachyura: Portunidae), with the recognition of four species. Raffle Bull Zool 58, 199-237.

25. Hajisamae S, Fazrul H, Pradit S (2015) Feeding ecology of Portunus pelagicus (Linnaeus, 1758) (Brachyura, Portunidae) in the southern gulf of Thailand: Influences of habitat, season, size class, shell stage and ovigerous condition. Crustaceana $\mathbf{8 8}$, 1163-1180.

26. Pittman S, McAlpine C (2003) Movements of marine fish and decapod crustaceans: process, theory and application. Adv Mar Biol 44, 205-294.

27. Kunsook C, Gajaseni N, Paphavasit N (2014) The feeding ecology of the blue swimming crab, Portunus pelagicus (Linnaeus, 1758), at Kung Krabaen Bay, Chanthaburi Province, Thailand. Trop Life Sci Res 25, 13-27.

28. Thongdonphum B, Meksumpun S, Meksumpun C, Thawonsode N, Sawadee B (2014) Variation of important nutrients proportion on phytoplankton distribution in Bang-tabun Bay, Phetchaburi Province, Thailand. Int J Environ Rural Dev 5, 100-104.

29. Samuel NJ, Soundarapandian P (2009) Fishery potential of commercially important crab Portuns sanguinolentus (Herbst) along Parangipettai Coast, South East Coast of India. Int J Anim Vet Adv 1, 99-104.

30. Nillrat S, Ngamcharoen K, Darbanandana T, Sawusdee A (2019) Biology and fisheries of blue swimming crab in Thailand. J Sci Technol Ubon Ratchathani Univ 21, 117-127. [in Thai]

31. Srisomwong M, Meksumpun S, Wangvoralak S, Thawonsode N, Meksumpun C (2018) Production potential of tidal flats for blood clam (Anadara granosa) culture in Bang-tabun bay, Phetchaburi Province. ScienceAsia 44, 387-395.

32. Safaie M, Pazooki J, Kiabi B, Shokri M (2013) Reproductive biology of blue swimming crab, Portunus segnis (Forskal, 1775) in coastal waters of Persian Gulf and Oman Sea, Iran. Iran J Fish Sci 12, 430-444.

33. Jentoft $S$, Chuenpagdee R, BarragÃąn-Paladines MJ, Franz N (2017) The Small-scale Fisheries Guidelines: Global Implementation, Vol 14, Springer, Cham, Switzerland.

34. Sukhsangchana C, Phuynoia S, Monthuma Y, Whanpetcha N, Kulanujareeb N (2020) Catch composition and estimated economic impacts of ghost-fishing squid traps near Suan Son Beach, Rayong Province, Thailand. ScenceAsia 46, 87-92.

35. Saramul S, Ezer T (2014) Spatial variations of sea level along the coast of Thailand: Impacts of extreme land subsidence, earthquakes and the seasonal monsoon. Glob Planet Change 122, 70-81.

36. Wouters B, Chambers D (2010) Analysis of seasonal ocean bottom pressure variability in the Gulf of Thailand from GRACE. Glob Planet Change 74, 76-81.

37. Hamley JM (1975) Review of gillnet selectivity. J Fish Res Board Can 32, 1943-1969.

38. Davies T, Beanjara N, Tregenza T (2009) A socioeconomic perspective on gear-based management in an artisanal fishery in south-west Madagascar. Fish 
Manag Ecol 16, 279-289.

39. Kamrani E, Sabili AN, Yahyavi M (2010) Stock assessment and reproductive biology of the blue swimming crab, Portunus pelagicus in Bandar Abbas coastal waters, northern Persian Gulf. J Persian Gulf 1, 11-22.

40. Kunsook C, Gajaseni N, Paphavasit N (2014) A stock assessment of the blue swimming crab Portunus pelagicus (Linnaeus, 1758) for sustainable management in Kung Krabaen Bay, Gulf of Thailand. Trop Life Sci Res 25, ID 41.

41. McClanahan T, Mangi S (2004) Gear-based management of a tropical artisanal fishery based on species selectivity and capture size. Fish Manag Ecol 11, 51-60. 


\section{Appendix A. Supplementary data}

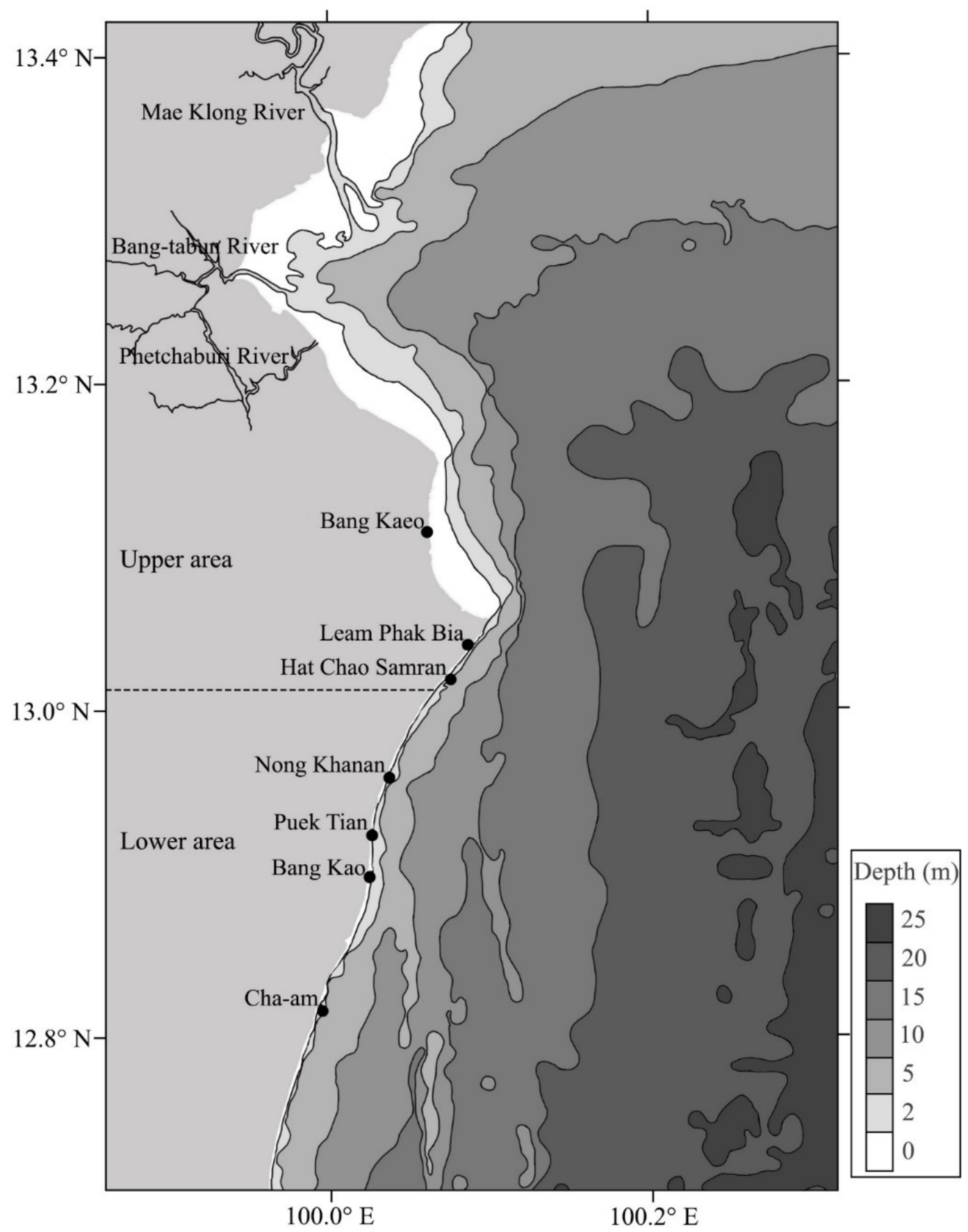

Fig. S1 The coastline of Phetchaburi Province in the Inner Gulf of Thailand showing the seven sampling sites along the coast in the upper and the lower areas. Major rivers close to the area are presented. The contour of sea depth is also provided in the map. 